\title{
Aa. Vv., «Bulletin des Amis d'André Gide», n. 153
}

\section{Emanuele Kanceff}

\section{(2) OpenEdition}

\section{Journals}

\section{Edizione digitale}

URL: http://journals.openedition.org/studifrancesi/9655

DOI: 10.4000/studifrancesi.9655

ISSN: 2427-5856

\section{Editore}

Rosenberg \& Sellier

\section{Edizione cartacea}

Data di pubblicazione: 1 décembre 2007

Paginazione: 693-694

ISSN: 0039-2944

\section{Notizia bibliografica digitale}

Emanuele Kanceff, «Aa. Vv., «Bulletin des Amis d'André Gide», n. 153», Studi Francesi [Online], 153 (LI I III) | 2007, online dal 30 novembre 2015, consultato il 13 janvier 2021. URL: http://

journals.openedition.org/studifrancesi/9655 ; DOI: https://doi.org/10.4000/studifrancesi.9655

Questo documento è stato generato automaticamente il 13 janvier 2021.

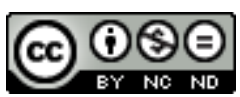

Studi Francesi è distribuita con Licenza Creative Commons Attribuzione - Non commerciale - Non opere derivate 4.0 Internazionale. 


\title{
Aa. Vv., «Bulletin des Amis d'André Gide», n. 153
}

\author{
Emanuele Kanceff
}

\section{NOTIZIA}

«Bulletin des Amis d'André Gide», n. 153, XL e année, vol. XXXV, janvier 2007, pp. 200.

1 Con quest'anno la storica rivista dell'Association des Amis d'André Gide compie quarant'anni, e la sua vitalità e giovinezza testimoniano agli studiosi e al pubblico dei lettori quanto sia valida e preziosa per gli studi. Questo numero, bipartito come spesso avviene in una parte di contributi scientifici e una di comunicazioni, riserva la sua prima parte agli interventi relativi al colloquio di Siena, 17 febbraio 2006, dal titolo Gide oggi/Gide aujourd'hui. Vi sono raccolti, oltre all'Introduzione di Catherine MAUBON - che tiene a spiegare come non vi sia stato nulla di celebrativo né alcuna occasione commemorativa nel Colloquio, ma soltanto il piacere di ritrovarsi a Siena attorno a un tema certamente fertile e "capitale" - sette interventi che illustrano, più o meno direttamente, il tema del convegno. Martine SAGAERT, Le charme inépuisable d'une œuvre... Les lignes de force d'un portrait, insiste sulla vitalità dell'opera di Gide oggi e ripercorre per meglio capirne le ragioni la sua biografia, con molti inevitabili riferimenti al Journal, all'importanza dei viaggi e anche all'Italia. Pierre MASSON, Écriture/réécriture de soi. Variations sur quelques scenes capitales, riflette sui due registri della scrittura gidiana, il presente fissato ed eternizzato, il passato rimesso in causa ed esorcizzato. Questa riscrittura costante dell'intimo non si limita a registrare la sua evoluzione, la condiziona e crea il personaggio. Gianfranco RUBINO, La narration gidienne. Entre discours et fiction, parte da un discorso di ricezione per constatare l'importanza della fiction nella produzione gidiana, al di là di ogni "discorso" e delle questioni che seppe sollevare questo "contemporaneo capitale" con la sua scrittura "riflessiva". Marielle MACÉ, «Demain, le souvenir». Gide historien de la littérature, si chiede se Ramon Fernandez avesse ragione nel qualificare Gide come lo scrittore meno "storico" e lo smentisce in parte 
analizzando le sue prese di posizione sul filo dell'opera. Jacqueline RISSET, La Poésie en question, prende a riferimento un divertente episodio inglese del 1917 che indurrà lo scrittore a "difendere" la poesia francese con la sua Antologie della "Pléiade". Quest'ultima viene puntualmente analizzata per riconoscerne i reali moventi e gli atteggiamenti dell'autore nei confronti del genere poetico. Sandra TERONI, Le Clerc militant, si chiede in sostanza se Gide sia veramente l'emblema del letterato viziato da estetismo, soggettivismo, preziosismo, come voleva Benda, e ciò la induce a una puntuale analisi delle prese di posizione dello scrittore di fronte agli eventi del suo tempo e delle tracce tutt'altro che tenui che l'opera ne porta, fino alla tarda pubblicazione di Littérature engagée. Stefano AGOSTI conclude il discorso sulla Actualité de Gide mettendo l'accento sulla sperimentazione incessante della sua scrittura e conducendo un lungo itinerario nell'opera, che lo porta a concludere sulla verità della parola poetica come sperimentazione, che formerebbe la sua principale ragione di attualità.

2 La seconda parte del volume offre parti dei diari inediti di Robert Levesque e di Jean Lambert, i Dossiers de presse di Amyntas, del Journal, di $\mathbb{E}$ dipe, e le consuete rubriche delle Lectures gidiennes e della Chronique bibliographique. 